\title{
EARLY COGNITION, COMMUNICATION AND LANGUAGE IN CHILDREN WITH FOCAL BRAIN INJURY
}

\author{
Developmental Medicine and Child Neurology, 1994, 36, 1076-1098
}

\author{
Anna Maria Dall'Oglio \\ Elizabeth Bates \\ Virginia Volterra \\ Matteo Di Capua \\ Grazia Pezzini
}

The aim of this research project was to study the first stages of cognitive, communicative and linguistic development in a group of Italian-speaking infants who had suffered focal brain lesions to the left or right hemisphere before the time when language acquisition would normally begin (i. e. prenatally or in the first months of life). This study is part of a continuing collaboration between laboratories in the USA and Italy, using many of the same inclusion and exclusion criteria to define the sample (Marchman et al. 1991, Thal et al. 1991a, Wulfeck et al. 1991), together with a parallel set of parental report instruments for the evaluation of early language and communication. The present study had a somewhat more limited focus than its us counterpart, involving a set of intensive case studies of six children followed longitudinally for the first two years of life. We concentrated on aspects of cognitive and communicative development, with special emphasis on the cognitive correlates of first words. A great deal is known about these aspects of development in normal children, furnishing a rich basis for the assessment of the effects of early brain injury (Camaioni et al. 1976; Bates et al. 1979, 1988).

The results presented here are relevant to two important but difficult theoretical issues in developmental neuropsychology:

the contribution of non-linguistic cognition to early language development, and the plasticity of language under conditions of focal brain injury.

The question of whether there is a relationship between language and cognition is often answered with a simple 'yes' or 'no'. At one extreme, it has been argued that language is a by-product of general intelligence, and that language development is invariably paced by the child's mental age*. At the other extreme, some theorists have argued that language is 'an independent module' (Fodor 1983) meaning that it should he nossihle for lan- guage to fall behind other aspects of cognitive development and/or to move ahead in children who are severely retarded in other respects. There is room for a number of intermediate positions between these two extremes. For example, specific aspects of early language development may be dependent on specific

\footnotetext{
*The assumption that language is a product of general intelligence is implicit in much of the literature on intelligence testing, where vocabulary subtests are often used as a short form to estimate total IQ. Of course, given the magnitude of the correlations between vocabulary tests and total IQ, one could just as easily argue that intelligence is a by-product of language. Piaget has offered a more explicit and- coherent version of the theory that language depends on more general cognitive structures (e.g. Piaget 1962). For a review of research on language development within the Piagetian tradition, see Bates and Thal (1990).
} 
'cognitive infrastructures' (e.g. forms of perception, memory, categorization and problemsolving) that have to be in place before the child can-take his or her next step in language development. Once some threshold level has been reached in these prerequisite skills, language may develop in domain-specific ways that have no counterpart in other mental systems (KarmiloffSmith 1993).

This study focused on specific behaviors that are known to predict the emergence of first words in normal children, with particular emphasis on the use of culturally derived gestures with common objects (e.g. using a comb or putting a telephone receiver to the ear). It has been argued that one-year-old children use these gestures to recognize, categorize or in some sense 'label' familiar objects: hence they may index the presence of an important cognitive substrate for naming. To assess these behaviors, we combined information from several sources, including laboratory observations, cognitive tests and parental reports.

We decided to concentrate on children with unilateral lesions of early onset because of their importance for our understanding of plasticity and specificity during the period in which the foundations of later language development are laid down (Bishop 1981). This is another area in which researchers have been caught between two extremes. As noted by Satz et al. (1990), neuropsychologists have tended to treat the opposition between equipotentiality (Lenneberg 1967) and early specialization (Dennis and Whitaker 1976, Kinsbourne and Hiscock 1983) as a 'yes/no' question: the two cerebral hemispheres either are, or are not, equipotential for language. Satz et al. (1990) argued instead that these are two poles of a continuum, and that individual children may display a range of outcomes somewhere between these two extremes, depending on a variety of factors that are still poorly understood, but which deserve investigation. We hoped that a prospective study of brain-injured children who were learning language for the first time would help us to understand the degree of hemispheric specialization that is evident at the beginnning of language learning, together with processes that underlie neural and/or behavioral plasticity in those children who ultimately achieve normal levels of language use.

It is generally assumed that the case for plasticity is' strongest in children who have suffered their injuries relatively early (Woods and Teuber 1978, Hecaen 1983, Riva and Cazzaniga 1986, Aram 1988), although contradictory evidence was presented by Annett (1973). Many older children with this etiology are indis-tinguishable from un- et al. 1990, Vargha-Khadem et al. 1991). However, findings from our American collaborators suggest that these children do display moderate to severe delays in the very first stages of language learning. This includes a significant delay in the onset of babbling and first words (observed in a longitudinal study of five children by Marchman et al. 1991) and delays in word comprehension, word production and early grammar, as noted in a combined cross-sectional and longitudinal study of 27 infants by Thal et al. (1991a). The delays observed by those authors occurred across the sample, regardless of side, size or intrahemispheric site of injury. However, delays in expressive (but not receptive) language were often more protracted in children with lesions extending into the posterior (retrorolandic) areas of the left cerebral hemisphere. The mixed picture that emerged from the study of Thal and colleagues illustrates the point raised by Satz et al. (1990), i. e. that there is a need to develop a theory of brainbehavior relations to explain the many points that individual children can occupy between the two extremes of equipotentiality and strong (irreversible) lefthemisphere specialization for language.

Although the sample of children available for the present study was relatively small, longitudinal findings of this kind are informative and relatively rare (see also Feldman et al. 1992, Levy et al. 1992). We were particularly impressed by the extraordinary individual differences that could be observed within this small sample. Each individual case made us reconsider the complex interactions that appear to hold among traditional neurological predictors such as lesion site,

\section{TABLE I}

\section{Grading system for lesion severity}

Grade Interpretation

o Normal

I Minimal ventricular dilatation or atrophy

2 Moderate ventricular dilatation or atrophy observed on $>3$ cuts on CT nr

3 Focal porencephaly (involving only one lobe) observed on $<3$ cuts on $\mathrm{CT}$ $n r$

$4 \quad$ Focal porencephaly (involving only one lobe) observed on $>3$ cuts on CT nr

5 Large porencephaly (involving_ multiple lobes) 
lines for future collaborative studies involving larger samples.

\section{Method}

\section{SUBJECTS}

We selected six subjects (one boy and five girls) who met the following inclusion criteria (see also Marchman et al. 1991, Stiles and Nass 1991, Thai et al. 1991a, Wulfeck et al. 1991): they had to have a single unilateral focal cortical lesion, either ischemic or hemorrhagic, identified on the basis of at least one neuro-imaging procedure (cranial ultrasound, CT scan or MRI scan), and the lesion had to have occurred before the end of the first year of life, after a pregnancy without persistent problems. Exclusion criteria included evidence of multiple or bilateral lesions, disorders that might produce more global brain damage (e.g. congenital viral infection, maternal drug or alcohol ingestion during pregnancy, bacterial meningitis, encephalitis and severe hypoxia), or a chronic lesion such as a tumor, or arteriovenous malformation (AVM). Like our American colleagues, we chose not to exclude. children with a history of seizures. The outcomes associated with seizure history are quite variable, and it may be premature to exclude children with a seizure history from studies of the short- and long-term consequences of early focal brain injury.

The sample included four children with lefthemisphere lesions (one frontal only, one parietal only, one frontal-parietal, and one temporalparietal) and two children with right-hemisphere lesions (both frontal only). To quantify lesion size, we used a grading system adapted from an earlier version by VarghaKhadem et al. (1985). This grading system is summarized in Table I. The neurological characteristics of the six subjects who met our criteria are summarized in Table II; additional details are provided in the results section, within individual case descriptions.

\section{PROCEDURE}

\section{Laboratory observations}

Each child was seen longitudinally over the first three years of life, at ages and intervals that varied in accordance with the age at which the child was first identified, the parents' schedule and the child's other medical needs. All visits took place in an observation room in the neuropsychology division of a pediatric hospital, equipped with a wide selection of age-appropriate toys. Both parents were present at every session, and were asked to comment on the child's performance in structured tasks and/or free play, providing background information on the child's typical performance during comparable activities at home. At each session, periods of free play were interspersed with ents also sought an evaluation by a speechlanguage pathologist at the same pediatric hospital. Summaries of this evaluation are provided, where relevant, in the general observations within each case report. Given the informal nature of all these observational data, no attempt was made to quantify them. Instead, we used the observations to supplement results obtained with formal cognitive testing and the language and communication questionnaires.

\section{Cognitive development}

Two conventional tests of infant cognitive development were used in this study: the Uzgiris-Hunt scales of psychological development (Uzgiris and Hunt 1975) and the Brunet-Lezine scale (Brunet and Lezine 1967)*. Both scales were administered on a longitudinal basis, although we allowed for some flexibility in the amount of testing that was attempted on any given visit, depending on the child's mood and attention span. The Uzgiris-Hunt scales cover five different areas of sensorimotor development: Object Permanence, Object Schemes, Means-End Relations, Operational Causality, and Spatial Cognition (a sixth scale for gestural and vocal imitation was omitted from this study, because it is redundant in many respects with the language and communication questionnaires, and the Brunet-Lezine language and sociability items). The Uzgiris-Hunt scales do not provide development quotients, so here we present a clinical description of the child's success or failure on these measures (compared with the approximate age at which normal children reach the ceiling on each scale in published research studies-see Uzgiris and Hunt 1987, Bates et al. 1979).

\footnotetext{
*Unfortunately there is very little norming information available for either the Brunet-Lezine or the Uzgiris-Hunt scales. The Brunet-Lezine is based on early descriptive research by Gesell, and provides quotients that map approximately (based on clinical experience) onto the scores obtained in more standardized intelligence tests. However, the scores have never been verified against a large norming sample. The UzgirisHunt only provides ordinal 'pass-fail' information, and also lacks systematic age-based norms. We chose these instruments because they are widely used in clinical practice and in clinical research throughout Italy and other parts of continental Europe, and because no better alternatives were available for research on cognitive development in this age range. At the time of writing there were no standardized infant tests with Italian norms, although an Italian norming of the Bayley scales is currently under way (Laicardi, personal communication).
} 
TABLE II

Neurological characteristics

\begin{tabular}{|c|c|c|c|c|c|c|c|}
\hline Case & Side & Site & Etiology & $\begin{array}{l}\text { Severity } \\
\text { grade }^{r}\end{array}$ & $\begin{array}{l}\text { Symptoms at } \\
\text { diagnosis }\end{array}$ & $\begin{array}{r}\text { Seizure } \\
\text { history }\end{array}$ & $\begin{array}{l}\text { Motor } \\
\text { deficit }\end{array}$ \\
\hline A. B. & Right & Frontal & $\begin{array}{l}\text { Undetermined } \\
\text { (?prenatal) }\end{array}$ & 1 & $\begin{array}{l}\text { Four-month } \\
\text { seizures }\end{array}$ & $\begin{array}{l}\text { Partial seizures } \\
\text { followed by } \\
\text { West syndrome }\end{array}$ & $\begin{array}{l}\text { Left arm } \\
\text { hyposthenia }\end{array}$ \\
\hline C. D. & Left & $\begin{array}{l}\text { Fronto- } \\
\text { parietal }\end{array}$ & $\begin{array}{l}\text { Vascular } \\
\text { (prenatal) }\end{array}$ & 5 & $\begin{array}{l}\text { Six-month right } \\
\text { hemiparesis }\end{array}$ & No seizures & $\begin{array}{l}\text { Right } \\
\text { hemiparesis }\end{array}$ \\
\hline E.F. & Left & Parietal & $\begin{array}{l}\text { Vascular } \\
\text { (perinatal) }\end{array}$ & 3 & $\begin{array}{l}\text { Neonatal } \\
\text { hypertonic } \\
\text { syndrome }\end{array}$ & $\begin{array}{l}\text { No seizures, EEG } \\
\text { abnormalities }\end{array}$ & $\begin{array}{l}\text { Right } \\
\text { hemiparesis }\end{array}$ \\
\hline G. L. & Left & Frontal & $\begin{array}{l}\text { Undetermined } \\
\text { (?prenatal) }\end{array}$ & I & $\begin{array}{l}\text { Three-month } \\
\text { seizures }\end{array}$ & $\begin{array}{l}\text { West syndrome } \\
\text { followed by rare } \\
\text { resistant partial }\end{array}$ & No deficits \\
\hline M.N. & Left & $\begin{array}{l}\text { Temporo- } \\
\text { parietal }\end{array}$ & $\begin{array}{l}\text { Vascular } \\
\text { (perinatal) }\end{array}$ & 5 & $\begin{array}{l}\text { Neonatal motor } \\
\text { deficit and } \\
\text { seizures }\end{array}$ & $\begin{array}{l}\text { seizures } \\
\text { West syndrome } \\
\text { followed by } \\
\text { resistant partial }\end{array}$ & $\begin{array}{l}\text { Right } \\
\text { hemiparesis }\end{array}$ \\
\hline Q.R. & Right & Frontal & $\begin{array}{c}\text { Pachygyria } \\
\text { (prenatal) }\end{array}$ & 4 & $\begin{array}{l}\text { Five-month } \\
\text { seizures }\end{array}$ & $\begin{array}{l}\text { seizures } \\
\text { Resistant partial } \\
\text { seizures }\end{array}$ & $\begin{array}{l}\text { Moderate } \\
\text { motor delay }\end{array}$ \\
\hline
\end{tabular}

'See Table I for explanation.

The Brunet-Lezine scales provide a single general developmental index, together with individual scores in four different areas: motor development, competence with objects, language and sociability. On this scale, scores above 90 are considered normal, 80 to 90 are below average (i. e. lownormal), 70 to 79 are considered borderline, and scores below 70 represent some degree of mental retardation $(60$ to $69=$ mildly delayed; 50 to $59=$ moderately delayed; 21 to $50=$ severely delayed; 0 to $20=$ profoundly delayed).

\section{Language and communication}

Three parental report instruments for the assessment of early language and communication were available for use in this study (Casadio and Caselli 1989, Dale et al. 1989, Camaioni et al. 1991, Dale 1991, Caselli and Casadio 1993, Fenson et al.

1993). Two of these are Italian versions of the MacArthur Communicative Development Inventories. In fact, the English and Italian scales have been developed in tandem over a 15-year period. For the English versions, norms are now available for more than 1800 children (Fenson et al. 1993a). A norming study of the Italian version is currently under way (Caselli et al. 1993), and norming data for 500 children between eight and 30 months of age were put at our disposal for the present study. Previous studies have demonstrated that the English and Italian scales both have high internal and testretest reliability, and that they demonstrate measures of the same constructs (for details, see Camaioni et al. 1991, Fenson et al. 1993).

The Infant Scale includes a checklist of words that commonly appear in receptive and expressive vocabularies during the period from eight to 16 months of age. The full scale contains a list of 396 words, with two columns next to each word, one for 'understands' and the other for 'says'. In addition, the Infant Scale includes a checklist of 64 communicative gestures (e.g. pointing and shaking the head to mean 'no') and object-related gestures (e.g. putting a telephone receiver to the ear) that are typically produced by children in this age range. Previous studies have shown that these communicative and symbolic gestures are highly correlated with the onset of language comprehension and/or language production (Bates et al. 1983, 1989; Acredolo and Goodwyn 1990; Bates and Thai 1990; Caselli 1990; Shore et al. 1990; Caselli et al. 1993b). Because it was clear to us that many of the children with focal lesions were markedly delayed in the onset of language and gesture, we decided not to make the parents administer the full Infant Scale. Instead we selected 70 words together with the 64 gestures from the checklist to create a less taxing and shorter version. Centile scores for this short version were derived by calculating scores on the 70 items for the 500 Italian children in the Italian norming study. (Current research by Fenson and his colleagues has shown that for English such 'derived short forms' preserve the validity and reliability of the 
centile scores for children aged 18 months or less. For children who continued to receive the short version of the Infant Scale because they were developing slowly (i.e. their scores were still below the median for 18 months), we could use the norms to assign age equivalents (e.g. to indicate that a 24-month-old child was performing at the median level for children who are 16 months of age).

Part I of the Toddler Scale contains a checklist of 686 words that are typical in the expressive vocabularies of infants between 16 and 30 months. Because parents of most normal children cannot keep track of word comprehension beyond 16 months of age, this checklist only asks the parents to indicate whether the child currently 'says' each of the words in question. Part II contains a series of questions about early grammar, including the presence/absence -of word combinations and typical examples of early multi-word speech. In the present study, the Toddler Scale was only used with a subset of the focal lesion children, at or beyond 22 months of age. If the child was still markedly delayed in language production (i. e. producing fewer than 10 words in total), we continued use of the short version of the Infant Scale after 22 months. The Toddler Scale can be used to assign centile scores to children aged 30 months or younger. For children who were developing slowly (i. e. equivalent to the median score for children at or below 30 months), we could use the same norms to derive age equivalents (i. e. 'language age').

A third language instrument, the Prelinguistic Communication Inventory, was given only to the parents of children who were still making virtually no progress in language. This questionnaire asks about the use of gestures, vocalizations and eyecontact in requests and in play. There are no norms available for this instrument. However, if parents indicated on this instrument that there were no signs of word comprehension and/or word production, this was assumed to be equivalent to a score of zero on the relevant MacArthur scale at that age level. 


\section{Results}

This section provides detailed descriptions of each individual, case, including background (parental education and child's biomedical history) and neurological information, as well as longitudinal data on behavioral development, i.e. general observations (from free play and parental

commentary during each laboratory visit), results of cognitive testing (on the

Uzgiris-Hunt and Brunet-Lezine scales), and information from the language and communication questionnaires. The Discussion gives a summary of results at the

group level, focusing on the two issues described in the introduction: the relationship between cognitive development and early language, and the contribution of

neurological factors to positive or negative outcomes in this age range.

\section{CASE HISTORIES}

Case 1: A.B.

A.B. was a female, born to parents with average to high levels of education. This was her mother's second pregnancy; the first ended in a miscarriage at two months due to unknown causes. For this reason, preventive anti-abortion therapy was used during her pregnancy with A.B. A sonogram at eight months suggested the presence of placental infarcts; however, the record contained no other reference to problems during pregnancy. A.B. was born at term, through normal delivery, and weighed $3810 \mathrm{~g}$ at birth. She was breast-fed for the first three months, and no problems of any kind were noted until the fourth month of life.

Neurological data. A.B. was referred to us at eight months with a right frontal grade 1 lesion. At four months, she presented with partial complex seizures focused around the anterior regions of the right hemisphere, markedly resistant to anticonvulsant medication. One month later the situation had evolved into a diffuse epileptogenic encephalopathy (West syndrome). ACTH therapy resulted in a gradual disappearance of seizures, with an improved EEG. Subsequently, small clusters of brief partial seizures (20 to $40 \mathrm{~s}$ in duration) were observed approximately every two months. These partial seizures decreased in frequency, and appeared to be well controlled, but mild motor symptoms were noted (diffuse global hypotonia, with weakness of the left arm). An MRI at eight months of age indicated a small region of high signal value in a subcortical area near the right lenticular nucleus. Results of a cT scan were negative.
Developmental data. We observed A.B. for a total of six-sessions, at eight; nine, 14_,-21, 29 and 35 months of age. At the first session, A.B. appeared to be markedly unresponsive, with little interest in visual or auditory stimuli. She neither cried nor smiled throughout the session. After the first cycle of ACTH, smiling reappeared; she reacted to auditory stimuli by seeking their source with her gaze, and she followed objects that moved in her visual field. She also picked up objects, but only with the right hand. Object manipulation improved in subsequent sessions, and at 14_months she was using her left hand. At the same 14_month session she was able to walk without support, and she communicated actively with adult observers by pointing and making requests. She also displayed some ability to name familiar objects in picture books, and she produced a number of culturally derived actions, including pushing a car back and forth while saying 'vroom', and alternately hugging, caressing and kissing a baby doll while saying 'cara' (Italian for 'dear', a word that adults typically use in modelling affectionate acts with dolls and stuffed toys). However, it was difficult to obtain evidence for language comprehension, since A.B. appeared to attend very little or not at all to requests like 'show me the baby's eyes'. At the 21-month session, it was clear that A.B. was still progressing very well in expressive language. She produced a wide variety of single words, including verbs like 'apri' and 'guarda' ('open' and 'look'), and she also used a few Italian function words in a reduced form (e.g. 'a bambola', an approximation to 'la bambola [the doll]'). Nevertheless, her response to verbal requests was still unreliable. By 29 months she was able to communicate in short sentences. Comprehension had improved, although she was often distracted in the middle of a response to verbal requests.

A.B. reached ceiling on the Uzgiris-Hunt Object Permanence scale at 14 months, well within the range reported in research on normally developing children (Bates et al. 1979, Uzgiris and Hunt 1987). However, on the other four scales she did not reach ceiling until 29 months, well beyond the ages usually reported for normal children (see Table III). Her low score on the Object Schemes scale was particularly noteworthy, since we know from our general observations during free play that A.B. was able to carry out culturally derived action schemes with familiar objects by 14 months of age. On the Brunet-Lezine (see Table IV), A.B. scored below normal levels on the general developmental index at the first two sessions, but she had moved to the border 
TABLE III

Uzgiris-Hunt- scales

\begin{tabular}{|c|c|c|c|c|c|c|}
\hline \multirow[t]{2}{*}{ Case } & \multirow{2}{*}{$\begin{array}{l}\text { Age at test } \\
\text { (yrs: mths) }\end{array}$} & \multicolumn{5}{|c|}{ Highest level reached on scales' } \\
\hline & & $I$ & $I I$ & $I V$ & $V$ & $V I$ \\
\hline \multirow[t]{3}{*}{ A. B. } & $0: 9$ & 4 & 2 & 4 & 3 & 1 \\
\hline & $1: 3$ & $14^{*}$ & 6 & - & 5 & 2 \\
\hline & $2: 5$ & - & $11^{*}$ & $7 *$ & $11^{*}$ & $10^{*}$ \\
\hline \multirow[t]{4}{*}{ C. D. } & $1: 4$ & 7 & $11 *$ & - & 5 & $10^{*}$ \\
\hline & $1: 6$ & 7 & - & 5 & 6 & - \\
\hline & $2: 0$ & 7 & - & 5 & 8 & - \\
\hline & $2: 3$ & $14^{*}$ & - & $7 *$ & $11^{*}$ & - \\
\hline \multirow[t]{2}{*}{ E.F. } & $1: 7$ & 11 & $11^{*}$ & $7 *$ & $11^{*}$ & $10^{*}$ \\
\hline & $1: 11$ & $14 *$ & & & & \\
\hline \multirow[t]{6}{*}{ G.L. } & $0: 5$ & 1 & 2 & 3 & 2 & - \\
\hline & $0: 9$ & 3 & 3 & 4 & 4 & 1 \\
\hline & $1: 0$ & 5 & 3 & 5 & 5 & 4 \\
\hline & $1: 2$ & 10 & 3 & 5 & 3 & - \\
\hline & $1: 7$ & $14^{*}$ & $11^{*}$ & 6 & $11^{*}$ & $10^{*}$ \\
\hline & $2: 0$ & - & - & $7 *$ & - & - \\
\hline \multirow[t]{6}{*}{ M.N. } & $1: 2$ & 3 & - & 4 & - & 1 \\
\hline & $1: 3$ & 3 & 5 & 4 & - & - \\
\hline & $1: 5$ & 5 & 5 & 4 & - & 6 \\
\hline & $1: 10$ & 5 & 6 & - & - & - \\
\hline & $2: 0$ & 4 & 8 & $7 *$ & 6 & 7 \\
\hline & $2: 6$ & 10 & 8 & - & 6 & 9 \\
\hline \multirow[t]{4}{*}{ Q.R. } & $0: 8$ & 5 & 3 & 3 & 3 & 1 \\
\hline & $1: 0$ & 3 & 5 & 5 & 5 & 3 \\
\hline & $1: 3$ & 3 & 6 & 5 & 7 & 5 \\
\hline & $2: 5$ & 3 & 6 & 5 & 7 & 7 \\
\hline 'Scale & $\mathrm{I}=$ Object & Permanence; & Scale & II = Mear & ds; Scale & $\mathrm{IV}=$ \\
\hline
\end{tabular}

of the low-normal range at 14_ months, and was well within the normal range at the last two sessions. Although this improvement was reflected on all four subscales, language was by far her strongest domain, while object competence never moved beyond low-normal.

A.B.'s parents did not fill out the infant questionnaire at $14^{1 / 2}$ months, so we have no further information on language and gesture to supplement our laboratory observations at that age. However, her strong performance in the Free Obcarrotions and an tha I onmura sosla of tho Rm guage questionnaires from 21 months. At 21 months, A.B.'s parents filled out the language portion of the Infant Scale only (the Gesture subscale was still not available at that time). Here they reported that A.B. could produce and understand all 70 of the language items. In the MacArthur norms for language production, this performance would place her at or above the 95th centile for normal children at 21 months of age. Since comprehension norms are not available beyond 18 months of age on this instrument, we could not nrovida santilas or oma amuirolants Horrovar it is 
the 18-month median for comprehension. At 29 months of age we administered the Toddler Scale, and A.B.'s parents reported an expressive vocabulary of 456 words. This score corresponds to the 65 th centile on the MacArthur norms for 29month-old Italian children. On part II of the Toddler Scale, A.B.'S parents reported that she was producing multi-word utterances such as 'furgone di babbo .[daddy's truck]' or 'io leggo [I read]', demonstrating an initial use of some Italian in- flections and function words. This report is compatible with our own laboratory observations. (See Fig. 1A for a summary of A.B.'s progress in vocabulary production, expressed in centile scores.)

\section{Summary.}

This case offers a profile of relatively unaffected language from the age of 141/2 months onward, despite persistent motor

TABLE I V

Brunet-Lezine scales

\begin{tabular}{|c|c|c|c|c|c|c|}
\hline \multirow[t]{2}{*}{ Case } & \multirow{2}{*}{$\begin{array}{l}\text { Age at test } \\
\text { (yrs: } m t h s)\end{array}$} & \multicolumn{5}{|c|}{ Individual scale scores } \\
\hline & & $\begin{array}{l}\text { Developmental } \\
\text { Index }\end{array}$ & Motor & Objects & Language & Sociability \\
\hline \multirow[t]{5}{*}{ A.B. } & $0: 8$ & 41 & 37 & 48 & 48 & 38 \\
\hline & $0: 9$ & 71 & 67 & 56 & 76 & 67 \\
\hline & $1: 3$ & 80 & 70 & 78 & 120 & 78 \\
\hline & $1: 9$ & 100 & 100 & 85 & 128 & 100 \\
\hline & $2: 5$ & 93 & 93 & 86 & 103 & 93 \\
\hline \multirow[t]{5}{*}{ C.D. } & $1: 4$ & 103 & 103 & 88 & 118 & 112 \\
\hline & $1: 6$ & 100 & 106 & 84 & 111 & 100 \\
\hline & $2: 0$ & 97 & 100 & 100 & 100 & 79 \\
\hline & $2: 3$ & 100 & 100 & 100 & 111 & 88 \\
\hline & $2: 7$ & 89 & 88 & 88 & 96 & 88 \\
\hline \multirow[t]{5}{*}{ E.F. } & $1: 7$ & 90 & 92 & 90 & 94 & 92 \\
\hline & $1: 11$ & 90 & 96 & 102 & 91 & 104 \\
\hline & $2: 3$ & 93 & 100 & 100 & 81 & 88 \\
\hline & $2: 6$ & 92 & 90 & 93 & 90 & 90 \\
\hline & $2: 9$ & 87 & 81 & 90 & 90 & 81 \\
\hline \multirow[t]{8}{*}{ G. L. } & $0: 5$ & 70 & 75 & 71 & 47 & 74 \\
\hline & $0: 6$ & 90 & 100 & 83 & 97 & 99 \\
\hline & $0: 9$ & 87 & 91 & 85 & 77 & 90 \\
\hline & $1: 0$ & 75 & 91 & 67 & 75 & 66 \\
\hline & $1: 2$ & 78 & 92 & 71 & 84 & 92 \\
\hline & $1: 7$ & 87 & 97 & 72 & 99 & 92 \\
\hline & $2: 0$ & 73 & 87 & 58 & 83 & 75 \\
\hline & $2: 5$ & 81 & 86 & 75 & 89 & 86 \\
\hline \multirow[t]{8}{*}{ M.N. } & $1:^{2}$ & 50 & 50 & 44 & 57 & 44 \\
\hline & $1: 3$ & 52 & 53 & 46 & 60 & 54 \\
\hline & $1: 5$ & 52 & 52 & 52 & 52 & 52 \\
\hline & $1: 10$ & 44 & 45 & 40 & 40 & 54 \\
\hline & $2: 0$ & 48 & 41 & 46 & 37 & 54 \\
\hline & $2: 4$ & 39 & 32 & 39 & 20 & 46 \\
\hline & $2: 6$ & 43 & 34 & 44 & 30 & 50 \\
\hline & $2: 10$ & 39 & 32 & 38 & 26 & 47 \\
\hline \multirow[t]{6}{*}{ Q.R. } & $0: 8$ & 87 & 77 & 96 & 87 & 8 \\
\hline & $1: 0$ & 78 & 82 & 74 & 74 & 82 \\
\hline & $1: 3$ & 66 & 80 & 67 & 60 & 73 \\
\hline & $1: 9$ & 73 & 90 & 66 & 71 & 71 \\
\hline & $2: 0$ & 69 & 87 & 62 & 62 & 68 \\
\hline & $2: 5$ & 61 & 72 & 58 & 52 & 52 \\
\hline
\end{tabular}

limitations and performance in the low-normal range on a number of non-linguistic tasks, combined with a reluctance to co-operate in structured testing. Because of this lack of cooperation, it is difficult to interpret low scores on the cognitive measures, but the overall profile suggests that language developed quickly in this child as soon as some threshold level of non-verbal cognition had been reached (see Discussion).

Case 2: C. D.

Background. C.D. was the dizygotic female twin of a healthy sister. Both parents had high levels of education. The twins were born at term by emer- 


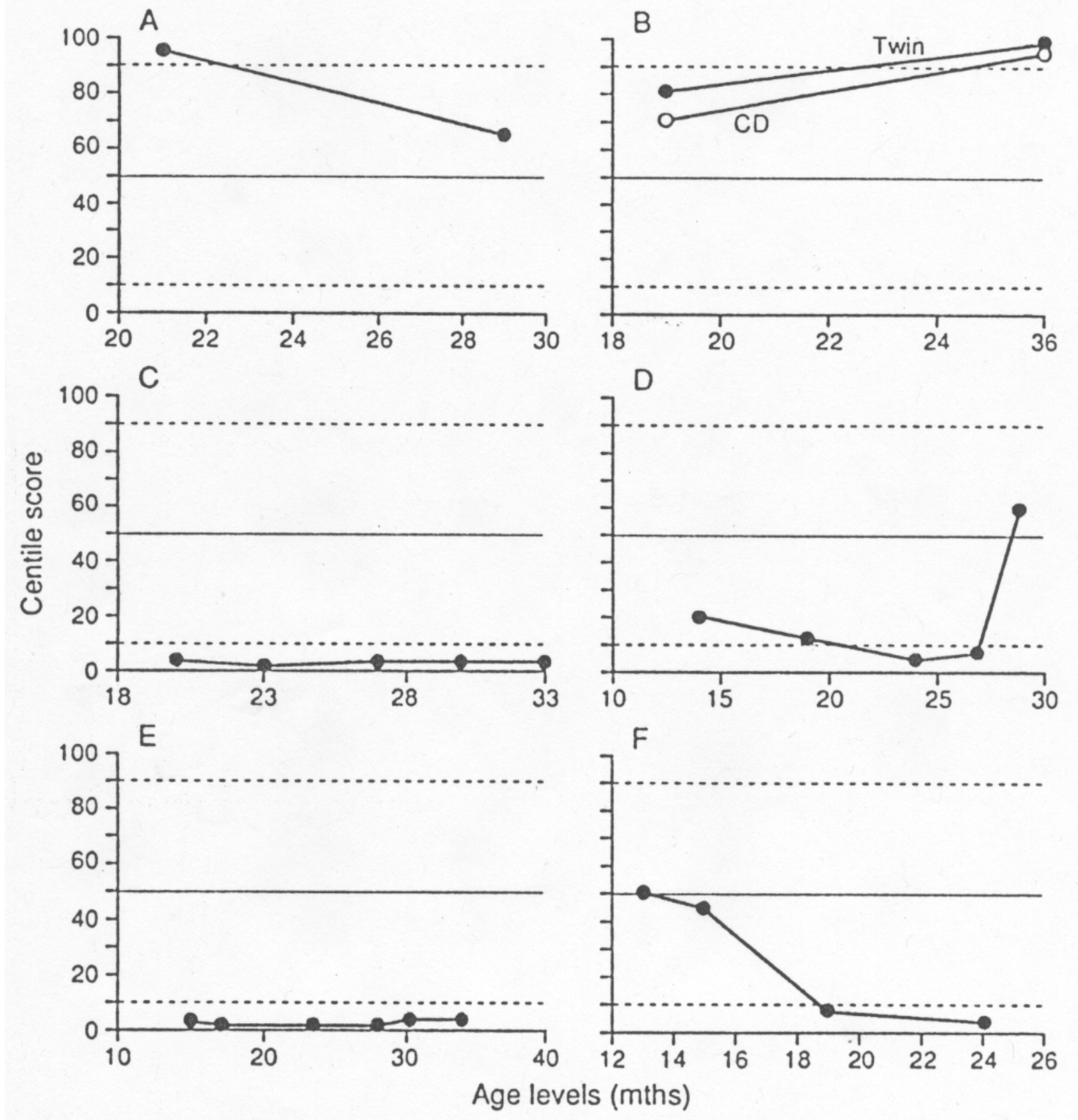

Fig. I. Centile scores for word production: (A) A.B., (B) C.D., (C) E.F., (D) G.L., (E) M.N. and (F) Q.R. 
normal range. She was placed in an incubator for six days, starting on the second day of life, for problems of thermoregulation. Her physical growth slowed noticeably around seven months of life, due to glucose intolerance, a situation that continued through the eighth and ninth months. After that point, growth was in the low-normal range but remained relatively constant.
Neurological data. C.D. was referred to us at 16 months with a fronto-parietal lesion in the left hemisphere, at a grade 5 level of severity. She presented a right hypotonic hemiparesis, particularly marked in the right arm. There was no evidence of seizures at this time or subsequently. A CT scan revealed a porencephalic cavity in the left fronto-parietal

region, communicating with the lateral ventricle and with the subarachnoidal space. The lesion was ascribed to prenatal events, possibly an ischemia in the area of the left Sylvian artery.

C.D. was observed in our laboratory for five successive sessions, at 16, 18, 24, 27 and 31 months of age. At the first observation at 16 months, C.D. appeared lively and vigilant. However, she could not yet walk with support (whereas her twin had walked without support at nine months), and she rarely used her right hand. During these observations, her communication was limited to pointing and imitating a few words. At 18 months C.D. was still unable to walk, and locomotion was limited to rolling and scooting, but use of the right hand had improved. Language production included a variety of single words and a few two-word combinations, but she rarely followed simple verbal commands from an adult. As noted in the case of A.B., it is difficult to determine whether this apparent lack of comprehension was due to a language problem or to a general unwillingness to co-operate. C.D. had began to walk without support by 24 months. At this age we also observed evidence of spontaneous symbolic play. At 27 months she produced sentences of three or more components, a level of fluency that continued through the 31-month session. Continued motor limitations

were observed throughout these observations, coupled with a lack of attention to the right hand.

On the Uzgiris-Hunt scale (Table III), C.D. was already at ceiling on the Means-End and Object Scheme scales at 16 months of age. Yet throughout the observations she continued to per- 
Spatial Relations). The two scales on which C.D. was most successful were the two that have been shown to correlate most consistently with communicative and linguistic development in normal subjects (Bates et al. 1979). However, in view of C.D.'s relatively good performance on the BrunetLezine, we need to consider the possibility that the low performance observed on the other three Uzgiris-Hunt scales may have underestimated C.D.'s non-verbal abilities. On the BrunetLezine scale (Table IV), the general developmental index for C.D. was within the normal range throughout the study. This was true despite the marked motor deficits and hemi-attention that she displayed throughout the five periods of observation. With regard to the four Brunet-Lezine subscales, C.D.'s strongest area at every test point was language. The other scales occasionally fell to the lownormal range.

In contrast to her performance on many of the cognitive measures, C.D.'s language development fell consistently within the highnormal range. At 19 months her parents filled out the Infant Scale for C.D. and her healthy twin sister. They reported 42 words in production, corresponding to a centile score of 70 on the MacArthur norms. Her parents also reported 62 words in comprehension and 41 gestures for C.D. Because the MacArthur norms for comprehension and gesture end at 18 months, we could not provide centile scores; nor could we provide age equivalents for a child who was already above the 18-month median level. However, it is clear that C.D. was performing well within or above the normal range for comprehension and gesture. For C.D.'s healthy twin, the parents reported 50 words in production, corresponding to a centile score of 80 . They also reported 60 words in comprehension and 47 gestures, which means that C.D.'s twin was also performing well above the 18-month median. Hence C.D. and her sister both appeared to be developing normally, and they were developing at comparable rates on all three aspects of early language and communication. At 26 months C.D.'s parents filled out the Toddler Scale, again for both children. For C.D. they reported an expressive vocabulary of 599 words, which would place her above the 95th centile for her age; for 
her twin, they reported a total of 670 words, also well above the 95th centile. On part II of the Toddler Scale, the parents reported that C.D. could produce sentences of up to four components (e.g. '(Own name) caduta, fatta bua [(Own name) fell, made boo-boo;', correctly inflected for gender). They also reported a number of sentences that indicated nascent control over verb conjugation. This level of grammatical development was exactly what we would expect for an Italian child in this age range (Bates 1976, Leonard et al. 1992, Pizzuto and Caselli 1992, Caselli and Casadio 1993). (See Fig. $1 \mathrm{~s}$ for a comparison of data on vocabulary production for C.D. and her twin, expressed in centile scores.)

Summary. C.D.'s expressive language abilities appeared to be well within the normal to highnormal range at all the relevant sessions, although evidence for language comprehension was mixed, due perhaps to her reluctance to follow adult requests. Her non-verbal profile was uneven, and included informal evidence for deficits in attention, but her performance on the Brunet-Lezine was consistently within the normal range. For these reasons, C.D. can be viewed as our best case, with sparing of both verbal and non-verbal abilities.

\section{Case 3: E. F.}

Background. E.F. was a third-born female with two healthy older sisters, eight and five years of age. Both parents have low to average levels of education. After a normal pregnancy, E.F. was born at the 34th week of gestation; labor was induced due to pyelonephritis of pregnancy. E.F. weighed $1650 \mathrm{~g}$ at birth. She presented with neonatal asphyxia and remained in hospital for 2 months; she was in intensive care for the first few days due to respiratory problems.

Neurological data. E.F. was referred to us with a subcortical grade 3 lesion in the left hemisphere. A CT scan revealed a moderate left ventricular dilatation with a small cavity $(4 \mathrm{~mm}$ in diameter) laterally to the central part of the left cerebral ventricle. Despite an absence of seizures, EEG analyses produced evidence of slow and epileptogenic abnormalities localized to the parietal regions of the left hemisphere. Based on these findings, anticonvulsant therapy was initiated. The child gradually showed hypertonus of the right side, particularly of the upper limb.

Developmental data. E.F. was referred to us at 19 months of age, and was observed at five sessions at 19, 23, 27, 30 and 33 months of age. E.F.'S parents reported that she sat by nine months, E.F. took the initiative in exploring toys, and communicated with her parents and the observers through eye-contact, showing, pointing and using other gestures. She produced a few single words and seemed to understand simple verbal commands. In all her activities, however, she relied predominantly on her left hand, using the right only for support. By 23 months, although E.F.'s mother described her as a timid child, she was quite extrovert in the laboratory setting and began to repeat words frequently. This picture was somewhat different by the 27-month session, when E.F. began to be very resistant to interaction with the observers, and all testing required the presence and assistance of the parents. Because E.F. was still not using her right hand, she began to receive physical therapy twice a week. The mother noted at this age that E.F. 'chatters a lot, but often seems to say words like a parrot, without any real meaning'. At the 30-month session we began to note a slight but pervasive clumsiness. She also displayed considerable difficulty in building tasks, e.g. constructing a simple bridge of blocks after an adult model. She continued to rely heavily on gestures to communicate her needs, and showed considerable impatience if she was not understood, although some novel use of single words was noted (e.g. the word 'ball' to refer to a picture of the moon). At this time, the parents requested a more extensive examination by a speech therapist. The therapist (a member of our research team) reported that E.F. could produce utterances of two or three words, together with pronouns, articles and a number of other function words. However, speech intelligibility was low, due to problems such as frequent elision of the first syllable of multisyllabic words. Furthermore, E.F. was unable to carry out verbal commands that required more than one simple action. Symbolic play was also quite immature at this point. This general picture continued through the 33 -month session, despite some improvement in her motor and constructional abilities. The mother reported a clear improvement in language comprehension, although this was not evident from E.F.'S behavior in the laboratory.

On the Uzgiris-Hunt scales, E.F. was already at ceiling on all but the Object Permanence scale at the 19-month session (Table III). On the Brunet-Lezine (Table IV), E.F.'s general developmental scores were within the normal range at all sessions except the final observation, when her overall score was just below average. Examination of the four subscales shows that E.F.'s strongest area was Object Competence. 
At 19 months, parental report indicated that E.F.'s communication was restricted almost entirely to gestures (such as giving, showing and pointing) accompanied by simple vocalizations. Three words were reported in her expressive vocabulary, all names for family members: 'mamma, papa' and 'nonna [grandmother]'. At 20 months E.F.'s parents filled out the Infant Scale and reported an expressive vocabulary of four words, a receptive vocabulary of 35 words, and 32 gestures. The production score placed E.F. well below the fifth centile for normal children at 20 months of age. Because the MacArthur norms for Comprehension and Gesture do not go beyond 18 months, we could not provide centile scores for these two measures. However, the norms can be used to derive age equivalents for children who are progressing slowly. For E.F., the resulting scores were 14 months for Word Production (a six-month delay), 12 months for Comprehension (an eight-month delay) and 13 months for Gesture (a seven-month delay). The finding that E.F.'s age equivalence in word comprehension actually lagged behind word production is compatible with her mother's remark that 'she chatters a lot ... without any real meaning'. Because E.F.'s expressive language development was proceeding slowly, we readministered the Infant Scale at 23 and 27 months. At 23 months, E.F. could produce eight words (well below the fifth centile for her age), could understand 49 words, and had 32 gestures. These scores correspond to age equivalents of 16 months, 15 months and 13 months, respectively. At 27 months, her parents reported 25 words in production (again well below the fifth centile), 53 words in receptive vocabulary, and 38 gestures. Although this was an improvement over the 23-month session, it still meant that E.F. was performing at age equivalents of 18 months, 16 months and 15 months, respectively.

At 30 and 33 months we administered the Toddler Scale. This form yielded continuing evidence of delay in language development compared with normal controls. At 30 months, expressive vocabulary was now reportedly at the 94word level, still well below the fifth centile. On Part II at this age, her parents reported that her word combinations were restricted to a few twoword sentences. This overall level of lexical and grammatical performance was typical of normal Italian children at 19 to 20 months, suggesting a delay of almost one year in E.F.'s Case. At 33 months, her expressive vocabulary had expanded to 185 words-a score which would still leave E.F. in the bottom 5 per cent for normal children of her age, equivalent to the average child at 21 months of age. At this point E.F.'s parents also noted an tions at 31 months (see above). Figure lc summarizes E.F.'s progress in vocabulary production expressed in centile scores, while Figure 2a illustrates her language development in a different form, comparing her language age and chronological age (i.e. 'expected language age') at each point during the study.

Summary. E.F. did show improvement in language and communication skills over the observation period, but remained seriously delayed in language compared with controls at each age. Because cognitive and motor development were persistently within the lownormal range, E.F. appears to offer a profile in which language lagged behind other aspects of cognitive development.

Case 4: G.L.

Background. G.L. was a first-born male. Both parents had average levels of education. The pregnancy proceeded normally for the first four months; some symptoms of a possible miscarriage appeared at that time, although there were no contractions or signs of blood spotting, and the mother was advised to minimize her physical activities for the remainder of the pregnancy. G.L. was born 13 days beyond term, after a normal labor and delivery, and weighed $3470 \mathrm{~g}$.

Neurological data. G.L. was referred to us with a left frontal lesion at a grade I level of severity, probably of prenatal origin. The CT scan revealed enlargement of the anterior horn of the left lateral ventricle, while EEG examinations suggested the presence of a hypsarrhythmia over the left hemisphere. He presented with West syndrome, the first seizures occurring around three months of age after the first vaccination, appearing in clusters of massive spasms. After this he was admitted to hospital for a month, and ACTH therapy brought the seizures under control. Therapy with phenobarbital was continued for the remainder of the study period. No tonicpostural symptoms were noted at any point.

Developmental data. G.L. was observed in our laboratories at a total of eight sessions, at four, six, nine, 12, 14, 19, 24 and 29 months of age. In addition, parental reports on language development were obtained at 14, 19, 24, 27 and 29 months.

In the first session G.L. was vigilant and showed considerable interest in objects (which he touched without grasping).. He smiled and maintained eye-contact with adults, although there was a notable absence of vocalization. 

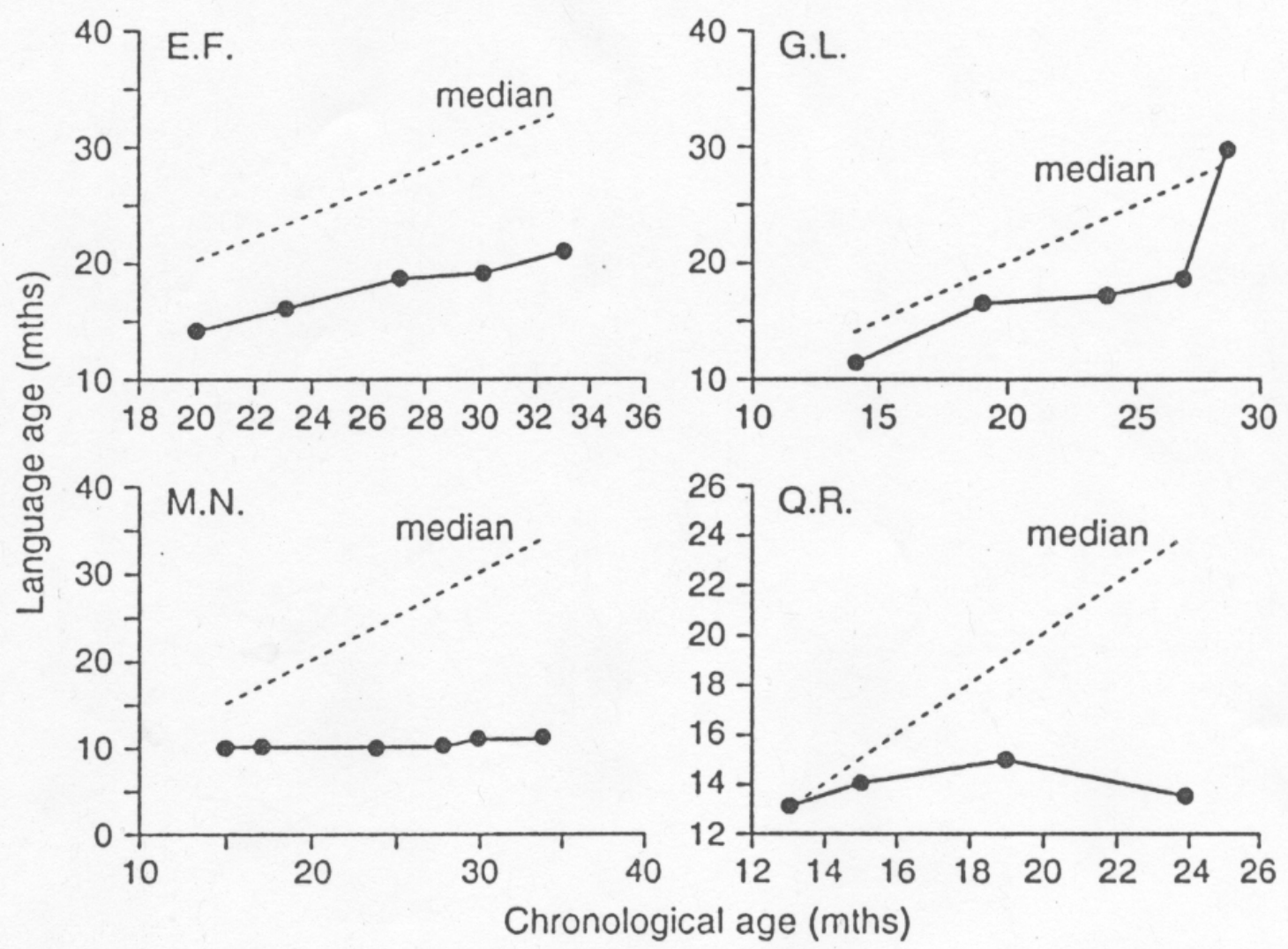

Fig. 2. Language age, based on word production, for E.F., G.L., M.N. and Q.R. 
At the six-month session he grasped objects and manipulated them with both hands for very short periods. He could also maintain a sitting position, and produced vowel sounds. At nine months his ability to manipulate objects showed that his attention span had increased, although his activities had not increased in complexity and were restricted primarily to oral exploration. His communication was limited to short modulated sounds with undifferentiated movements of the body. Although he could sit without support, he could not bring himself to a sitting position nor move about without help. At 12 months there were still no signs of a meaningful use of sound or of gestural or vocal imitation, although G.L.'s manipulation and exploration of objects had grown in complexity. By 14 months he could walk without support. Gestural and vocal imitation were noted, and he appeared to understand familiar words in context. His object play included some culturally appropriate actions with common objects. By two years, however, there was still little evidence of the emergence of meaningful speech, and his failure to develop language had become a matter of considerable concern to his parents. There was also very little evidence of symbolic play with toys or familiar objects beyond the simple schemes observed at 14 months. His actions were slow and clumsy. Evaluation by a speech therapist at this point revealed little evidence of language comprehension, with language production limited to a few stereotyped forms. G.L. began to attend a preschool group around this time, and also began regular sessions of psychomotor therapy. At 19 months his play with objects was somewhat more complex, and there was some evidence of imitation of simple actions by adults. He communicated at this session primarily through pointing. At 24 months he showed his first signs of preten play with objects, but only when initiated by the adult. Communication was still limited primarily to pointing. In the final session, at 29 months, he continued to manifest a very short attention span, and his play with objects was still quite immature. By contrast, G.L.'s language production had improved markedly, in pronunciation as well as vocabulary, and there was also evidence of a marked improvement in language comprehension.

By 19 months, G.L. had reached ceiling on all the Uzgiris-Hunt scales except for Operational Causality (Table ICI). Progress on the UzgirisHunt was slow before this point, and G.L. did not display conventional behavior with common objects on the Object Schemes scale until 19 months (although he did show such behavior in the Free Observations at 14 months). On the Brunet-Lezine (Table IV), G.L.'s general developmental index was between borderline and below average although G.L.'s weakest area was Object Competence (with scores that occasionally fell into the mildly or moderately retarded range).

G.L.'S parents filled out the Infant Scale for the first time at 14 months. Compared with the performance of normal Italian infants at the same age, this level of word production was below normal (20th centile, corresponding to the average score at 11_ months), but comprehension and gesture were well above normal levels $(>95$ th centile for comprehension, above the 18-month median, and 58th centile for gesture, equivalent to the median at 15 months). The gesture section of the Infant Scale was particularly important here, since it showed that G.L. was indeed capable of performing culture-specific actions with common objects at 14 months of age (e.g. putting a telephone to the ear), even though he did not display such behaviors on the Uzgiris-Hunt Object Schemes scale. At 19 months, his receptive vocabulary on the Infant Scale was close to ceiling (with a knowledge of 68 of 70 words, above the 18-month median), and 39 gestures were reported (equivalent to the median for normal children at 16 months). However, expressive vocabulary was still delayed, since he only used nine of 70 words, corresponding to a centile score of 13 and an age equivalent of 16_months. At 24 months we asked his parents to complete the Toddler Scale, on which G.L. obtained an expressive vocabulary score of only 27 words, well below the fifth centile, with an age equivalent of 17 months. However, G.L.'s list of 27 words included a few function words that are rare in children with vocabularies this small, such as 'perché' ; why]'. At 27 months, reported vocabulary on the Toddler Scale had reached 117 words; although this represented a sharp increase since the previous session, it still corresponded to performance in the bottom fifth centile at 27 months, and an age equivalent of 18 months (i.e. an 8-month delay). At this age, G.L.'S parents also reported the onset of word combinations. At 29 months G.L.'s expressive vocabulary expanded markedly, reaching a total of 514 words, and there was increased evidence of sentence use. This vocabulary score placed G.L. ahead of the median for his age (at the 60th centile), equal to the median for children aged $\geq 30$ months. In view of G.L.'s earlier delays, this represented a startling increase in relative expressive language ability that is rarely observed within the normal range. (Fig. $1 \mathrm{D}$ gives a summary of G.L.'s progress in word production, expressed in centile scores; Fig. 2B shows a different view of the same data, in language age vs chronological age.)

Summary. G.L. provides our most interesting example of recovery from an initial delay in expres- 
gesture is not surprising, given the growing evidence that normal comprehension and normal use of gesture are positive for recovery from an expressive delay (Thal et al. 1991b). However, G.L.'S language burst occurred without a concomitant increase in any of our non-verbal cognitive test scores, which were still below normal on the Brunet-Lezine.

Case 5: M. N.

Background. M.N. was a first-born female. Both parents had a high level of education. The pregnancy proceeded normally until the eight month when M.N. was born preterm after a spontaneous but complicated labor due to the presence of a short umbilical cord. Her birthweight was $2600 \mathrm{~g}$. She was nursed in an incubator for the first month of life and fed maternal milk through a nasogastric tube. M.N. presented with seizures in the neonatal period, and underwent surgery for cyanotic heart malformation at two months.

Neurological data. M.N. was referred to us at 14 months, with a left temporo-parietal lesion at a grade 5 level of severity. She presented at birth with an intraventricular hemorrhage in the left hemisphere, confirmed by CT and cerebral sonogram. The CT scan revealed an extensive and marked porencephalic cavity in the left temporoparietal area, with concomitant signs of unilateral atrophy. M.N. presented with West syndrome at the age of seven months, followed by partial complex seizures resistant to the anti-epileptic drugs. At the first observation the EEG revealed slow and epileptogenic abnormalities over the left hemisphere. At the tonic-postural level, M.N. displayed a right hemiparesis, which was less severe in the lower limb, and a right homonymous hemianopia. Regular physical therapy was initiated early in the first year, and continued throughout the observation period.

Developmental data. M.N. was observed in our laboratory at eight sessions, at 14, 15, 17, 22, 24, 28, 30 and 34 months. At the first session she appeared to be a tranquil and happy baby. She was able to sit by herself, and her parents reported that she had begun to sit without support two months earlier. When manipulating objects, M.N. made no use at all of her right hand. At the 17-month session, M.N.'S communication with adults in the laboratory setting was restricted to a few imitative routines and/or requests, and she would extend her arm towards what she wanted without looking at the adult. However, she had finally begun to walk without assistance. At the 22-month session (the first after five months of seizures and hospitalization), she did not seem to have developed in alone. There were clear signs of oromotor apraxia, including continual drooling and (according to the mother) problems with chewing. Despite these worrying signs, she still appeared lively and attentive in her interactions with adults. At the 24month session, her interactions with objects were still undifferentiated and perseverative (e.g. throwing toys repeatedly), and there were no changes noted in communication. At 28 months we saw the first signs of language comprehension, when M.N. carried out simple verbal commands from her parents. Some of her motor problems had begun to resolve: there was a marked improvement in oral-facial movements, and more voluntary movement of the right leg, but walking had still not returned and there was no spontaneous use of the right hand. At 30 months the right hand was still not being used, and locomotion was still restricted to scooting from a sitting position. M.N. had begun to imitate new gestures and activities modelled by the adult. However, the laboratory observations revealed no signs of word production. By the final session at 34 months M.N. was able to stand alone, although she still could not walk. There was little or no spontaneous use of the right arm, although she could lift her right hand on command. Her play with objects now included conventional actions (e.g. using a comb), but no examples of word production were observed.

M.N. scored well below normal levels on all our cognitive measures across the period of observation. On the Uzgiris-Hunt scales (Table III), she reached ceiling only on the Operational Causality scale, and only at 24 months of age; on the other scales she remained far below the levels reported for normal children at every session. However, she had started to play with everyday objects in a conventional way by 29 months, suggesting that one prerequisite for language was finally in place. On the Brunet-Lezine sale (Table IV), M.N.'s scores on the general developmental index fell into the moderate to severely retarded range throughout the study period. Examination of the individual subscales suggested that this pattern of retardation was the same in every area, although language was clearly her worst area by 28 months.

In line with the overall developmental picture yielded by our laboratory observations and cognitive tests, parental reports of language and communication underscored a marked delay in all areas. Because M.N. was developing so slowly, we only gave her parents the Prelinguistic Communication Inventory at the first sessions. The results suggested that M.N.'s communication at 15 months was restricted to gestures of giving and occasional pointing, together with a few routines (e.g. blowing raspberries, and rocking or dancing 
entiated sounds. There were still no signs of word comprehension. The situation had not changed very much by 17 months, except that M.N. now produced the gesture 'ciao [i.e. hi/bye)', and showed some evidence of understanding the three words 'no', 'mama' and 'pappa' (the Italian baby word for food). Her parents reported that M.N. actually produced fewer vocalizations at this age than two months earlier. At 24 months, the only change reported by the parents consisted of evidence that she understood the single word papa [daddy]'. At 28 months the parents reported that she used gestures, especially pointing, much more often. At this age, M.N.'s parents were asked to complete the Infant Scale, on which they reported no words in production (far below the fifth centile), 31 words in comprehension, and 21 gestures (including some conventional schemes with objects). These scores corresponded to age equivalents of 10,11_ and 12 months, respectively. At 30 months of age, her parents reported her first real word in production (the word 'papa [daddy]'), together with 42 words in comprehension and 27 gestures. The age equivalents for these scores are 10 months, 14 months and 12 months, respectively. At 34 months, her production was unchanged, while word comprehension had risen to 45 words (equivalent to median scores at 15 months) and gestures now totalled 29 (still equivalent to median scores at 12 months). (Fig. 1 E gives a summary of progress in word production, expressed in centile scores; Fig. 2c compares language and and chronological age.)

Summary. Among all the children described in this study, M.N. displayed the most worrying profile. Her language, cognition and motor _evelopment were all markedly delayed from the 'beginning of the observation period, and no development of any kind was noted in the first weeks after her bout of seizures at 1 months. She began to improve slowly after the seizures were brought under control, but at the same slow pace and with the same marked delays that had been noted before these episodes began. Notwithstanding the slow overall pace of development, it is interesting that the very first signs of meaningful speech (i.e. the reported appearance of the first word around 30 to 34 months) appeared just after M.N. had begun to display conventional presymbolic acts with objects (e.g. using a comb). Hence M.N. preserved the language-cognition patterns that are so often observed at this stage in normal children, although the same events were occurring 18 to 22 months after the age at which they usually appear.

Case 6: Q. R.

Background. Q.R. was a second-born girl with a complications during pregnancy, and Q.R. was born at term with a normal delivery, weighing $3700 \mathrm{~g}$. Breast-feeding continued until five months of age, during which time her development proceeded normally.

Neurological data. Q.R. was referred to us at eight months of age. She had been admitted to hospital for the presence of seizures three or four times per day, from the age of five months. During her stay in hospital she was diagnosed as having a right frontal lesion at the grade 4 level of severity. Magnetic resonance imaging revealed focal pachygyria. Results of the neurological examination were within normal limits, except for a slight kinetic apraxia of the left hand. An EEG examination showed ictal and interictal abnormalities in the right frontal lobe. Anticonvulsant therapy was initiated, but her seizure profile was resistant to anticonvulsants and occasional seizures occurred during the period of study. Between the eight- and 12-month sessions she experienced a sharp increase in tonic seizures (up to 40 per day), and there was a marked worsening in the EEG, including diffuse anomalies. By the next session at 15 months, after the introduction of phenytoin, seizures were markedly reduced, and restricted to brief periods of motor arrest with fixation to the right. Given this seizure profile, it is interesting that Q.R. did make some progress in language and cognition in the first phases of our study, and it is perhaps equally important that her progress stalled when her seizures were brought under control.

Developmental data. Q.R. was observed in our laboratory for six sessions, at eight, 12, 15, 21, 24 and 29 months. In the first session, Q.R. appeared attentive and vigilant. She vocalized frequently, picked up objects, explored them manually and orally, and tried to retrieve them if they were taken away. She was able to sit without support for only a few moments at a time. At the 12-month session, after several weeks of increased seizure activity, there was little sign of continued psychomotor development. Her behavior with objects was quite simple and primitive, and mainly restricted to oral exploration and throwing. Nevertheless, she remained attentive and interested in objects and games that we proposed, continued to vocalize frequently and displayed a small repertoire of routines. At 15 months she was able to maintain a sitting position. At this point she had also begun to walk with support, and was active and mobile. Play with objects remained primitive, with only brief periods of attention to any single object or action. There was little sign of comprehension or compliance with simple verbal requests, or of gestural or vocal imitation. In the next sessions at 19 and 21 months, further progress was noted at the motor level. Although progress in play and language was slow, she had begun to produce a few words, coupled with increased evidence of word comprehension. 
Q.R. did not reach ceiling on any of the Uzgiris-Hunt scales during the observation period (Table III). On the Brunet-Lezine (Table IV), Q.R.'s General Mental Index started at the lownormal range at eight months and then varied between low-normal and borderline. Motor development was Q.R.'s strongest area. Object Competence fell within the mildly to moderately retarded range from 15 months.

Because Q.R. was developing so slowly in the first sessions, we gave her parents the Prelinguistic Communication Inventory at 12 months of age. At this point they reported that Q.R. could carry out a few routines (e.g. playing 'pat-a-cake', pretending to cough on command and blowing raspberries). Her way of requesting an object was to reach for it, while maintaining eyecontact with the object itself. Babbling in repeated consonantvowel sequences had appeared by this point. She would turn if her name was called, and she could understand a total of six words. We asked Q.R.'s parents to complete the Infant Scale by the next session. At 13 months they reported three words in production, 36 words in-comprehension and 10 gestures, corresponding to the 50th, 40th and 45th centiles, respectively. Although Q.R. did not produce conventional objectassociated gestures on the Uzgiris-Hunt scales at this age, her gestural report did include a few examples of this kind (e.g. putting a telephone receiver to the ear and sniffing a flower). By 15 months there was a slight improvement in both language and gesture, although the profile was quite mixed: six words in production (45th centile), 45 words in comprehension (up to the 70th centile), and 18 gestures (bottom fifth centile). The picture changed markedly after this point. At 19 months, her parents reported a total of only seven words in production (eighth centile), 47 in comprehension (age equivalent of 16 months), and 20 gestures (age equivalent of 12 months). These numbers suggested that progress in language and communication had slowed markedly since the previous session, compared with the progress that is usually observed in normal children between 15 and 19 months. At the final session at 24 months, her parents reported an expressive vocabulary of only five words. This was actually less than at the previous session and placed Q.R. well below the fifth centile for normal children at 24 months (age -equivalent of 13 _ months). The parents did report some progress in word comprehension (55 words, age equivalent of 17 months) and gesture (37, age equivalent of 14 _ months), but it was clear that Q.R. was now seven to 10 months behind her peers in language and communication. (See Fig. 1F for a summary of Q.R.'S progress in word production, expressed in centile scores. Fig. 2D presents a different view, comparing language age with chronological age.)

Summary. Q.R. started off surprisingly well in language and communication, despite her seizure activity, but her relative level of performance (compared with normal controls at each age) decreased over time in every area. Instead of catching up, Q.R. appeared to be falling further behind,

\section{Discussion}

There was considerable variability in the linguistic, cognitive and neurological profiles displayed by the six children who

participated in this study. Here we present a brief summary of these profiles, and

then consider their relevance for two issues: the relationship between language

and cognition during this period of development, and the contribution of neurological- factors to these languagecognition profiles.

A.B. had a small (grade 1) right frontal lesion, with concomitant motor problems, and she required anticonvulsant therapy throughout the study. Her expressive language was normal from the age of 14 months, despite cognitive scores in the low-normal range, but it was difficult to obtain similar evidence concerning language comprehension due to her unwillingness or inability to attend to verbal requests. 
C.D. had a large (grade 5) frontoparietal lesion in the left hemisphere; there was no evidence of seizures and no use of anticonvulsant drugs, but she did experience motor problems throughout the observation period (including underutilization of the right hand and significant delays in the attainment of motor milestones). C.D. performed in the highnormal range on measures of language development throughout the study and, like A.B., did not co-operate with our attempts to elicit language comprehension. Unlike A.B., she did perform well on many measures of non-verbal cognition.

E.F. had a left parietal-subcortical grade 3 lesion. She did not experience seizures, but anticonvulsant therapy was initiated because of EEG abnormalities, and motor problems were noted (including a right hemiparesis). Unlike A.B. and C.D., E.F. was markedly delayed in the development of expressive language. This was true despite her normal performance on measures of nonverbal cognition.

G.L. had a small (grade 1) lesion in the frontal regions of the left hemisphere. Although there were no frank motor deficits, he had problems with seizures and received anticonvulsant therapy throughout the period of study. G.L. displayed a language profile that contrasted markedly with those of A.B. and C.D. (who showed sparing of language) and with E.F. (who showed persistent language delays). G.L.'s parents reported very high levels of language comprehension and good use of gesture from 14 months of age, but his expressive language lagged far behind normal levels between 14 and 27 months. Between 27 and 29 months, his expressive language (reported and observed) underwent a remarkable growth, passing from the eighth to the 60th centile for expressive vocabulary, accompanied by the onset of grammar. This spurt was compatible with his early comprehension scores, but it was not accompanied by any evidence of a leap forward in nonverbal cognition. Indeed, his performance on cognitive tests was continually in the low-normal or mildly retarded range throughout the course of the study.

In contrast with the first four cases, M.N. and Q.R. both showed evidence of significant delay in every area. M.N. had a large (grade 5) lesion in the temporoparietal regions of the left hemisphere, with recurrent seizures and continued motor problems. Although she did make some progress in language and communication, her performance was consistently within the mildly retarded range on almost all our measures. Q.R. had a large right frontal lesion (grade 4), with recurrent seizures and accompanying delays in motor development. Early in the study her overall performance was in ering the extent of , seizure activity), but her language seemed to fall further and further behind after 15 months (the point at which phenytoin was introduced to bring her seizures under control), and she failed to show any progress at all during the period when normal children undergo substantial growth.

\section{RELATIONSHIP BETWEEN LANGUAGE AND COGNITION}

Clearly this sample provides a number of distinct language-cognition profiles. Two children showed a relatively even performance across domains: C.D. (who did quite well across the board) and M.N. (who was quite delayed on all measures). One child (A.B.) performed better in expressive language than we might have expected, given her delays in cognition. Another child (E.F.) was further behind in language than we would have expected, given normal performance in cognition. The most unusual profiles were displayed by G.L. and Q.R.. G.L. began with marked delays in most areas of functioning except language comprehension and gesture, but then experienced a remarkable burst in expressive language ability that was not accompanied by any equivalent increase in his non-verbal scores. Q.R. began within the normal range of language and (to a lesser extent) nonverbal cognition, but fell further and further behind during the study.

It is clear from these profiles that there is no simple across-the-board correlation between linguistic and cognitive measures in this age range. However, our data do support a 'cognitive infrastructure' or 'cognitive threshold' model of the relationship between linguistic and nonlinguistic abilities during these early stages of development. In particular, none of the children produced meaningful speech without prior or concomitant production of culturally derived actions with common objects (such as using a comb or putting a telephone receiver to the ear). Previous studies have shown that normal children use these gestures to 'label' or 'recognize' familiar things around the same point in development that naming begins. It appears from our data that children with focal brain injury cannot or do not begin to use language productively until such cognitive prerequisites are in place. After that point, language can move ahead or lag behind non-verbal measures to a considerable extent (for a review of similar evidence from other clinical populations, see Karmiloff-Smith 1993, Bates et a!. 1994).

We need to add two caveats to this cognitive infrastructure model. First, our conclusions apply primarily to the cognitive correlates of early 
vocabulary. Although our data suggest a degree

of dissociation between language and cognition after this point, there may be other correlational or cause-and-effect relations that apply at later stages of development (e.g. at later stages in grammar or during the emergence of narrative discourse). Second, it is important to keep in mind that most cognitive tests require the child to collaborate in some way (i. e. to carry out an action or to find where an object has been hidden). The same is also true for most measures of language compre hension. By contrast, our measures of free speech and conventional gestures with objects both involved spontaneous and voluntary activity. This may be one reason why there was a relatively close relationship between these gestures and the emergence of spontaneous naming, and it may also explain why spontaneous naming appears to be dissociated from other cognitive tests after a critical threshold has been reached. Compliance is difficult to obtain even in normal children in the one- to two-year age range; but it is particularly difficult with children who are at risk for attentional deficits and/or problems with compliance. These children may appear to be delayed in language comprehension and in conventional tests of cognitive ability, despite apparent sparing of spontaneous language and gesture. Our ability to draw conclusions about these critical abilities would be greatly improved if tests of comprehension, perception and reasoning could be developed that rely less on compliance with adult commands. In this regard, we are particularly interested in some recent advances in cognitive electrophysiology, and techniques that may permit the assessment of comprehension and pattern recognition during passive observation of visual and auditory events (e.g. Nelson and Salapatek 1986; Molfese 1990; Mills et al. 1993, 1994).

\section{NEUROLOGICAL PREDICTORS}

\section{Lesion site}

Lesion site, considered in isolation, was a poor predictor in this sample. Our best case (C.D.) and our worst case (M.N.) both had injuries extending to the left posterior (retrolandic) cortex. We found a similar contrast between our two righthemisphere cases, both with injuries restricted to the frontal regions: A.B. did very well in language (although she did show some delays in non-verbal cognition), while Q.R. was lagging behind in all areas of language and cognition by the end of the study.

Most previous studies of children with focal brain injury have failed to find consistent effects of lesion site (for a review, see Riva et al. 1992). In a series of sodium amytal tests of adults with a history of early left-hemisphere brain 
injury, Rasmussen and Milner (1977) demonstrated that 40 per cent of their patients had developed right-hemisphere dominance for language, 20 per cent had a mixed pattern with some functions mediated by the left and others mediated by the right, while another 40 per cent showed lefthemisphere dominance for language despite extensive injury to that hemisphere. Righthemisphere dominance was more likely if the patient's lefthemisphere injury involved the classic perisylvian (temporo-parietal) language zones, but there were clear exceptions to this general tendency. These results suggest that a considerable degree of inter- and intrahemispheric reorganization for language can take place in this population. Within the age range studied here, Thai et al. (1991a) found delays in the onset of receptive and expressive language, regardless of lesion site. However, they reported that children with lesions extending into left posterior regions tended to display more protracted delays in expressive (but not receptive) language. In our data, this was true for M.N. and E.F., but not for C.D. The fact that C.D. deviated from the left-posterior pattern reported by Thal et a!. (1991a) may have had something to do with other neurological factors.

\section{Lesion size}

Lesion size, like lesion site, appears to have no direct influence on language and cognition profiles when it is considered in isolation, but it may interact in interesting ways with other factors. Our best case (C.D.) and our worst case (M.N.) both had very large left-hemisphere lesions, but there was some correlation between behavioral outcomes and lesion size in our two right-hemisphere cases: A.B. (a linguistically advanced child with a grade 1 frontal lesion) and Q.R. (a linguistically delayed child with a grade 4 frontal lesion). In addition, the two children who (eventually) showed profiles with language ahead of cognition were the two with very small frontal lesions: A.B. (with a grade 1 lesion in the right frontal cortex) was ahead in language from the beginning of the study; G.L. (with a grade 1 lesion in the left frontal cortex) lagged behind in expressive (but not receptive) language until 29 months, when a remarkable burst in language ability was observed. Putting - this evidence together, the most serious exception to the expected site/size effects appears to be C.D., who performed well in all areas despite extensive injury to the left hemisphere.

Thal et al. 's (1991 a) study also revealed no linear effect of lesion size on language outcomes. However, they did find a surprising non-linear effect: the best linguistic outcomes were observed in children with very small (grade 1) or very large (grade 5) lesions to the right or left hemisphere. switching all language functions to the undamaged hemisphere at a relatively early point in development. Some support for this idea has come from an electrophysiological study by Mills et a!. (1994), who reported that linguistic recovery in toddlers with focal brain injury appears to be accompanied by a shift towards normal languageassociated potentials in the undamaged hemisphere. By contrast, children with mid-sized lesions may continue using the damaged hemisphere for a longer period of time, resulting in more protracted behavioral delays. Finally, it may be possible for children with very small lesions to follow normal or near-normal patterns of hemispheric mediation, resulting in relatively mild and/or short delays in language development. If this hypothetical ushaped pattern is correct (see Irle 1990 for a summary of results in primate lesion studies that support this hypothesis), then it may be the case that C.D. switched to righthemisphere mediation of language acquisition at a relatively early point in development; as a result, she was able to keep up with her healthy twin sister (a pressure that should also be considered when evaluating C.D.'s positive outcome).

\section{Motor deficits}

In this small sample, motor deficits appeared to be entirely unrelated to language outcome (see Riva et al. 1986). C.D. and M.N. displayed right hemiparesis, and yet they had completely different linguistic and cognitive outcomes. The only child in our sample without motor problems was G.L., whose profile(expressive delays despite spared comprehension, followed by a surprising growth in expressive language) might have led one to believe that there were motor deficits. We may hypothesize that frank motor deficits have little effect on early language and cognition, if the child has enough motor ability to permit him/her to explore the environment.

\section{Seizure disorders}

Ideally, we would like to study the effects of focal brain injury in the absence of seizure disorders. Unfortunately, this is difficult to do: children with focal lesions are relatively rare in the first place, and most children with early focal brain injury display seizure disorders at some point in their development (Pantaleoni et al. 1988). It does appear that seizure disorders and/or anticonvulsant therapy play a role in the cognitive and linguistic outcomes observed in these childrenalthough their effect is (again) not entirely straightforward. Of the six children in our study, four had seizure disorders (A.B., M.N., Q.R., G.L.) and one (E.F.) received anticonvulsant medication despite the absence of seizures, because of the presence of EEG 
below the mean on measures of nonverbal cognition. The only child who performed at or above normal levels in all domains was C.D., who showed no signs of seizures and did not receive anticonvulsant therapy. If our speculations about lesion size and compensatory switching are correct, then the presence or absence of seizure disorders may help to explain the contrast between C.D. and M.N. Perhaps C.D. was able to display the kind of plasticity that is so often discussed in the focal lesion literature while M.N. was not, because C.D. was not hampered by seizures or by the damping effect of anticonvulsant drugs.

The relatively good linguistic outcomes observed in A.B. and (by the end of the study) G.L. occurred despite their seizure history. This suggests that it may be premature to exclude children with seizure activity from research on the effects of early focal brain injury. It is unsettling to note that Q.R. was progressing within the

normal range in language and communication up to 15 months of age, despite severe and persistent seizures, and we may speculate that Q.R.'s healthy hemisphere (the left hemisphere in this case) was able to mediate normal progress in language despite sporadic interference from the diseased hemisphere. The introduction of phenytoin at 15 months was successful in bringing Q.R.'s seizures under control, but the coincidental arrest of progress in language and communication is a matter of some concern. At the very least, we recommend the continued study of early language development in children with and without seizure histories, as an aid to clinical research and the management of children with neurological deficits. These factors must be kept in mind when interpreting correlations between lesion site and behavioral outcomes.

\section{Conclusion}

It is possible that early language outcomes in children with focal lesions are determined by more than one factor, including some that we have not considered here, such as preterm birth, hypoxia in conjunction with early heart conditions, and demographic factors such as parental education. There is also a great deal of variability in the timing of early language milestones, even within the normal range (Fenson et al. 1993). Healthy, normally developing children at 16 months of age may have no words at all, or more than 100 words. By 24 months, some normal children still have fewer than 50 words, while others have vocabularies of more than 500 words and speak in lengthy sentences (see Bates et al. 1994, for a review). When studying children with focal brain injury, we have no way of knowing what profile we might have seen if that injury had not oc- way of pooling information to obtain a large enough sample of infants with early focal brain injury to clarify all of these factors. Fortunately, collaborative efforts of this kind are currently under way.

Although we are aware of the limitations of small-sample studies, some conclusions can be drawn even from a single case (Shallice 1988, Bates et al. 1991). Case studies -cannot- tell us what-patterns of sparing and impairment are typical in a given population, but they can tell us whether a given profile is possible. At the neural level, the present study demonstrates that language can emerge on schedule in some children with extensive left-hemisphere damage, and that serious delays can be observed in children whose left hemisphere appears to be intact. This kind of result is not new in the literature on focal brain injury in children, but it adds support to theories of plasticity and the capacity for reorganization following lesions that often lead to irreversible aphasia when they occur in an adult. At the behavioral level, the present study also shows that certain aspects of early language and communication can develop in children with serious delays in nonverbal cognition, and vice versa. However, the nature of this dissociation appears to have serious limitations. For example, despite widely divergent patterns of growth and delay, none of the children in this sample displayed evidence of expressive language before they were able to use conventional gestures with familiar objects (e.g. using a comb or putting a telephone receiver to the ear). Because this kind of symbolic or presymbolic activity has been linked to the emergence of first words in normal children and in many other clinical populations, the discovery of a similar link in children with focal brain injury lends support to some variant of the cognitive infrastructure hypothesis. In short, small-sample studies can be used to test strong hypotheses about mental and neural development, although such studies must be combined with evidence from other sources.

\section{Accepted for publication 24th March 1994.}

\section{Acknowledgements}

This research was supported by the Italian $\mathrm{Na}-$ tional Council of Research, through a trilateral grant directed by E. Bates, F. Maccagnani and V. Volterra, and by the US National Institute for Deafness and Communication Disorders, through a program project directed by Elizabeth Bates. Additional support was provided by the CNR Project on Prevention and Control of Disease Factors.

Authors' Appointments

Anna Maria Dall'Oglio; Matteo Di Capua; Grazia 
Children's Hospital and National Medical Research Institute, 'Bambino Gesu', Rome, Italy. *Elizabeth Bates, Departments of Psychology and Cognitive Science, Center for Research in Language 0526, University of California at San Diego, 9500 Gilman Drive, La Jolla, CA 92093-0-
26, USA. Virginia Volterra, Institute of Psychology, Italian National Council of Research (CNR), Rome, Italy.

*Correspondence to fourth author.

\section{SUMMARY}

The authors report a longitudinal study of the first stages of cognitive, communicative and linguistic development of six Italian-speaking infants with unilateral brain lesions acquired before the point at which language acquisition normally would begin. Substantial variability was observed in the language-cognition profiles displayed by these children. To unify these diverse profiles, the authors propose a 'cognitive infrastructure' or 'threshold' model of early language development, in which the appearance of speech depends on the presence of certain cognitive prerequisites; once those are in place, some degree of dissociation between linguistic and cognitive development can be observed. The contribution of neurological factors to these profiles appears to be complex, suggesting an interaction between lesion site, lesion size and the presence of seizure disorders and/or anticonvulsant drugs.

\section{RESUME}

Les premières connaissances, la communication et le langage des enfants avec lésions cerebrates localisées Les auteurs rapportent une étude longitudinale des premières etapes de développement de la connaissance, de la communication et du langage de six nourrissons parlant italien et presentant des lésions cérébrales unilatérales avant l'âge où le langage commence normalement. Une variabilité significative fut observée dans les profils langage/cognition présentés par ces enfants. Pour unifier ces divers profils, les auteurs proposent une 'infra-structure cognitive' ou un modèle 'a seuil' du developpement linguistique précoce selon lesquels l'allure du langage dépend de certains pré-requis cognitifs; une fois ceci en place, quelques degrés de dissociation entre les développements linguistiques et cognitifs peuvent être observés. L'influence des facteurs neurologiques sur ces profils apparaît complexe, suggérant une interaction entre le siège de la lésion, la taille de la lésion, la présence d'une comitialité et/ou traîtement anti-comitial.

\section{ZUSAMMENFASSUNG}

Frühe Wahrnehmung, Kommunikation and Sprache bei Kindern mit fokalem Hirnschaden

Die Autoren berichten von einer Langzeitstudie über die ersten Stadien der kognitiven, kommunikativen und sprachlichen Entwicklung bei sechs italienisch sprechenden Kindern mit unilateraler Hirnläsion, die sie vor Beginn der Sprachentwicklung erworben hatten. Es wurde eine erhebliche Variabilität bei den Sprach-Wahrnehmungsprofilen dieser Kinder festgestellt. Um diese verschiedenen Profile zu vereinheitlichen, schlagen die Autoren ein 'cognitives Infrastrukttir'-,oder 'Schwellen' Modeli für die frühe Sprachentwicklung vor, bei dem der Beginn der Sprache von dem Vorliegen gewisser cognitiver Vorbedingungen abhängt; wenn die einmal vorhanden sind, kann eine gewisse Dissoziation zwischen Sprach- und Wahrnehmungsentwicklung beobachtet werden. Der Einfluß neurologischer Faktoren auf diese

Profile scheint komplex zu sein, was vermuten läßt, daß zwischen Lokalisation der Lasion, Größe der Läsion und dem Vorliegen von Krampfleiden und/oder der Einnahme von antikonvulsiven Medikamenten eine Interaktion besteht.

\section{RESUMEN}

Cognición, communicación y lenguaje precoces en ninos con lesión cerebral focal Los autores aportan un estudio longitudinal de los cuatro estadios de desarrollo cognitivo, comunicativo y lingüístico en seis ninos de habla italiana con lesion cerebral unilateral, adquirida antes de momento en que normalmente se inicia la adquisición del lenguaje. Se observó una variabilidad substancial en los perfiles cognición-lenguaje. Para unificar estos diversos perfiles, los autores proponen una 'infraestructura cognitiva' o modelo de 'dintel' del desarrollo precoz de lenguaje, en el cual la aparición del lenguaje depende de la presencia de ciertos prerequisitos cognitivos. Cuando estos están presentes puede observarse cierto grado de disociación entre el desarrollo linguistico y el cognitivo. La contribución de factores neurológicos a estos perfiles parece complejo, sugiriendo una interacción entre el punto de la lesión, el tamaño de ésta y la presencia de convulsiones y/o una terapía anticonvulsiva. 
Acredolo, L. P., Goodwyn, S. W. (1990) 'Sign language among hearing infants: the spontaneous development of symbolic gestures.' In Volterra, V., Erting, C. (Eds.) From Gesture to Language in Hearing and Deaf Children. Berlin: Springer, pp. 68-78.

Annett, M. (1973) 'Laterality of childhood hemiplegia and the growth of speech and intelligence.' Cortex, 9, 4-33.

Aram, D. M. (1988) 'Language sequelae of unilateral brain lesions in children.' In Plum, F: (Ed.) Language, Communication and the Brain. New York: Raven Press, pp. 171-197.

- Gillespie, L., Yamashita, T. (1990) 'Reading among children with left- and right-brain lesions.' Developmental Neuropsychology, 6, 279-290.

Bates, E. (1976) Language and Context. New York: Academic Press.

- Thal, D. (1990) 'Associations and dissociations in language development.' In Miller, J. (Ed.) New Directions in Research on Child Language Disorders. Boston: College Hill Press, pp. 147-168.

- Benigni, L., Bretherton, I., Camaioni, L., Volterra, V. (1979) The Emergence of Symbols: Cognition and Communication in Infancy. New York: Academic Press.

- Bretherton, I., Shore, C., McNew, S. (1983) 'Names, gestures and objects: symbolization in infancy and aphasia.' In Nelson, K. (Ed.) Children's Language, Vol. IV. Hillsdale, NJ: Erlbaum, pp. 59-125.

- - Snyder, L. (1988) From First Words to Grammar: Individual Differences and Dissociable Mechanisms. New York: Cambridge University Press.

- Thal, D., Whitesell, K., Oakes, L., Fenson, L. (1989) 'Integrating language and gesture in infancy.' Developmental Psychology, 25, 100.11019.

Appelbaum, M., Allard, L. (1991) 'Statistical constraints on the use of single-case studies.' Brain and Language, 40, 295-329.

Dale, P., Thal, D. (1994) 'Individual differences and their complications in language development.' In Fletcher, P., MacWhinney, B. (Eds.) Handbook of Language Acquisition. Oxford: Oxford University Press.

Bishop, D. V. M. (1981) 'Plasticity and specificity of language localization in the developing brain.' Developmental Medicine and Child Neurology, 23, 251-255.

Brunet, O., Lezine, I. (1967) Scala di Sviluppo Psicomotorio della Prima Infanzia. Florence: Organizzazioni Scientifiche.
Turin: Boringhieri.

- Caselli, M. C., Longobardi, E., Volterra, V. (1991) 'A parent report instrument for early language assessment.' First Language, 11, 345-359.

Casadio, P., Caselli, M. C. (1989) 'I1 primo vocabolario del bambino: gesti e parole a 14 mesi.' Età Evolutiva, 33, 32-41.

Caselli, M. C. (1990) 'Communicative gestures and first words.' In Volterra, V., Erting, C. (Eds.) From Gesture to Language in Hearing and Deaf Children. Berlin: Springer.

Casadio, P. (1993) 'Sviluppo lessicale e prima grammatica nel secondo anno di vita.' Età Evolutiva, 45, 5-21.

Sanderl, L. (1993a) 'A parent report study of lexical and grammatical development in Italian.' Paper presented at the Sixth International Congress for the Study of Child Language, Trieste, Italy, July 1993.

Volterra, V., Camaloni, L., Longobardi, E. (1993b) 'Svi luppo gestuale e vocale nei primi due anni di vita.' Psicologia Italiana, 4, 62-67.

Dale, P. (1991) 'The validity of a parent report measure of vocabulary and syntax at 24 months.' Journal of Speech and Hearing Research, 34, 565-571.

- Bates, E., Reznick, S., Morisset, C. (1989) 'The validity of a parent report instrument of language at 20 months.' Journal of Child Language, 16, 239-250.

Dennis, M., Whitaker, H. (1976) 'Language acquisition following hemidecortication: linguistic superiority of the left over the right hemisphere.' Brain and Language, 3, 404-433.

Feldman, H. M., Holland, A. L., Kemp, S. S., Janosky, J. E. (1992) 'Language development after unilateral brain injury.' Brain and Language, 42, 89-102.

Fenson, L., Dale, P., Reznick, S., Thal, D., Bates, E., Hartung, J., Pethick, S., Reilly, J. (1993). MacArthur Communicative Development Inventories: Technical Manual. San Diego: Singular Press.

Fodor, J. (1983) Modularity of Mind. Cambridge, MA: MIT/Bradford Books.

Hecaen, H. (1983) 'Acquired aphasia in children: revisited.' Neuropsychologia, 21, 581-587.

Irle, E. (1990) 'An analysis of the correlation of lesion size, localization and behavioral effects in 283 published studies of cortical and subcortical lesions in old-world monkeys.' Brain Research Review, 15, 181-213.

Karmiloff-Smith, A. (1993) Beyond Modularity. Cambridge, MA: MIT Press/Bradford Books.

Kinsbourne, M., Hiscock, M. (1983) 'The normal and deviant development of functional later- 
III, 4th Edn. New York: John Wiley,. pp. 158280.

Lenneberg, E. (1967) Biological Foundations of Language. New York: John Wiley.

Leonard, L., Bortolini, U., Caselli, M. C., McGregor, K., Sabbadini, L. (1992) 'Morphological deficits in children with specific language impairment: the status of features in the underlying grammar.' Language Acquisition, 2, 151-179.

Levy, Y., Amir, N., Shalev, R. (1992) 'Linguistic development of a child with a congenital localised L.H. lesion.' Cognitive Neuropsychoogy, 9, 1-32.

Marchman, V., Miller, R., Bates, E. (1991) 'Babble and first words in children with focal brain injury.' Applied Psycholinguistics, 12, 1-22.

Mills, D., Coffey, S., Neville, H. (1993) 'Language acquisition and cerebral specialization in 20-month-old children.' Journal of Cognitive Neuroscience, 5, 326-342.

_ _ _ (1994) 'Changes in cerebral reorganization in infancy during primary language acquisition.' In Dawson, G., Fischer, K. (Eds.) Human Behavior and the Developing Brain. New York: Guilford Press, pp. 427-455.

Molfese, D. (1990) 'Auditory evoked responses recorded from 16-month-old human infants to words they did and did not know.' Brain and Language, 38, 345-363.

Nelson, C., Salapatek, P. (1986) 'Electrophysiological correlates of infant recognition memory.' Child Development, 57, 1483-1497.

Pantaleoni, C., Milani, N., Riva, D. (1988) 'Il linguaggio nei bambini col focolaio epilettogeno emisferico.' Bollettino della Lega Italiana dell'Epilessia, 62/63, 119-120.

Piaget, J. (1962) Play, Dreams and Imitation. New York: Norton Press.

Pizzuto, E., Caselli, M. C. (1992) 'Acquisition of Italian morphology and its implications for models of language development.' Journal of Child Language, 19, 491-557.

Rasmussen, T., Milner, B. (1977) 'The role of early left brain injury in determining lateralization- of cerebral speech functions.' Annals of the New York Academy of Sciences, 299, 355-369.

Riva, D., Cazzaniga, L. (1986) 'Late effects of unilateral brain lesions sustained before and after age one.' Neuropsychologia, 24, 423428.

- - Pantaleoni, C., Milani, N., Fedrizzi, E. (1986) 'L'emiplegia acuta nell'infanzia: la prognosi neuropsicologica.' Rivista di Neuroscienza Pediatrica, 2, 239-250.
- Mitani, N., Pantaleoni, C., Devoti. M., Zorzil, C. (1992) 'Gli esiti a distanzia delle lesioni cerebrali emisferiche cogenite ed acquisite.' In Benton, A., Levin, H., Moretti, G., Riva, D. (Eds.) Neuropsicologia in età Evolutiva. Milan: Angeli, pp. 185-197.

Satz, P., Strauss, E., Whitaker, H. (1990) 'The ontogeny of hemispheric specialization: Some old hypotheses revisited.' Brain and Language, 38, 596-614.

Shallice, T. (1988) From Cognitive Neuropsychology to Mental Structure. Cambridge: Cambridge University Press.

Shore, C., Bates, E., Bretherton, I., Beeghly, M., O'Connell, B. (1990) 'Vocal and gestural symbols: similarities and differences from 13 to 28 months.' In Volterra, V., Erting, C. (Eds.) From Gesture to Language in Hearing and Deaf Children. Berlin: Springer, pp. 7992.

Stiles, J., Nass, R. (1991) 'Spatial grouping activity in young children with congenital left- and rightbrain injury.' Brain and Cognition, 15, 201-222.

Thal, D. J., Marchman, V., Stiles, J.. Aram, D., Trauner, D., Nass, R., Bates, E. (1991a) 'Early lexical development in children with focal brain injury.' Brain and Language, 40, 491527.

- Tobias, S., Morrison, D. (1991b) 'Language and gesture in late talkers: a one-year followup.' Journal of Speech and Hearing Research, 34, 604-612.

Uzgiris, I., Hunt, J. (1975) Assessment in Infancy: Ordinal Scales of Psychological Development. Urbana: University of Illinois Press.

- - (1987) Research with Scales of Infant Development. Hillsdale, NJ: Erlbaum.

Vargha-Khadem, F., O'Gorman, A.. IVatters, G. (1985) 'Aphasia and handedness in relation to hemispheric side, age at injury and severity of cerebral lesion during childhood.' Brain, 108, 677-696.

- Isaacs, E., Papaleloudi, H., Polkey. C., Wilson, J. (1991) 'Development of language in six hemispherectomized patients.' Brain, 114, 473-495.

Woods, B., Teuber, H. (1978) 'Changing patterns of childhood aphasia.' Annals of Neurology, 3, 273-280.

Wulfeck, B., Trauner, D., Tallal. P. (1991) 'Neurologic, cognitive and linguistic features of infants after focal brain injury.' Pediatric Neurology, 7, 266-269. 